\title{
Dolphin Signature Rhythms and the Non-Cacophonous Coyote: Rhythm, cognition and the animal umwelt
}

\begin{abstract}
Merlin Donald claims that "Rhythm is a uniquely human attribute; no other creature spontaneously tracks and imitates rhythms in the way humans do, without training."(Donald 1991: 186). This paper marshals a defense of animal cognitive capacity for thythm, especially as it manifests in communicative acts. The conclusions is that some animals, specifically, coyotes (canis latrans) and bottlenose dolphins (tursiops truncatus) do exhibit much of what Donald demands of naturally rhythmic creatures, and as such, they manifest the precursors of more sophisticated conceptual-linguistic understanding.
\end{abstract}

Animal cognition is often considered to be fairly independent of signified meaning. That is, we often think about the animal umwelt in terms of 'nonconceptual cognition' and 'non-propositional content.' Bermudez (2003) suggests that thought and reasoning can occur without what we ordinarily think of as propositionally-based beliefs; Hauser (2000) offers the position that, if animals have beliefs at all, they neither understand that other animals have them nor have any insight into their own, and thus, their behaviors are not heavily based on propositional thought. Such non-verbal, asemiotic, uncategorized cognizing might still find itself exemplified in such activities as music and dance, rhythm and song. In music we find expression, but not of concepts (or at least not of typical, abstract concepts such as justice or pi).

But evidence of animals that find themselves musically inclined is sparse. Indeed, Merlin Donald claims that "Rhythm is a uniquely human attribute; no other creature spontaneously tracks and imitates rhythms in the way humans do, without training." (Donald 1991: 186) This paper marshals a defense of 
animal cognitive capacity for rhythm, especially as it manifests itself in communicative acts. The conclusions are that some animals, specifically, coyotes (canis latrans) and bottlenose dolphins (tursiops truncatus), do exhibit much of what Donald demands of naturally rhythmic creatures, and as such, they manifest the precursors of more sophisticated conceptual-linguistic understanding.

While my conclusions may be taken to pertain to musical cognition, I will not focus on music qua song, symphony, or choreographed dance. Donald's claim certainly has merit if we restrict ourselves to musical works, i.e., no other creatures write piano concertos, and my cats do not spontaneously groove to my musical purchases, even in the face of my own enthusiasm. Rather, I will discuss two animal-based examples that, I hope, cause us to reconsider and refine Donald's claim, and lead us to understand rhythmic cognition a bit more deeply. I take rhythm then to be a necessary, but not sufficient condition for music, and examine its appearance in dolphins and coyotes without the additional factors that would develop rhythmicity into music qua symphony or concerto.

Shying away from musical rhythm allows me to avoid the boilerplate examples of whale song or bird song. First, it is not clear that whale song actually has rhythm except in the dullest of senses. While songs of whales (including especially Humpback and Blue) are repetitive and contain sub-phrases not unlike those in human musical constructions, and the repetitions are predictable within a specified time span, Donald's notion of thythm is far more complex, demanding that rhythm be spontaneously imitated, rehearsed and modified. ${ }^{1}$ That is, if

1 René Descartes foreshadows Donald's notion of the importance of spontaneous generation of symbolic meaning as pivotal in our measures of the cognition of others, whether human or animal. In a lengthy passage worth reading in full, Descartes separates humans and animals via the lack of spontaneous generation of linguistic signs: "[...] that there are no men so dull and stupid, not even idiots, as to be incapable of joining together different words, and thereby constructing a declaration by which to make their thoughts understood; and that on the other hand, there is no other animal, however perfect or happily circumstanced, which can do the like. Nor does this inability arise from want of organs: for we observe that magpies and parrots can utter words like ourselves, and are yet unable to speak as we do, that is, so as to show that they understand what they say; in place of which men born deaf and dumb, and thus not less, but rather more than the brutes, destitute of the organs which others use in speaking, are in the habit of inventing certain signs by which they discover their thoughts to those who, being usually in their company, have leisure to learn their language. And this proves not only that the brutes have less reason than man, but that they have none at all: for we see that very little is required to enable a person to speak; and since a certain inequality of capacity is observable among animals of the same species, as well as among men, and since some are more capable of being instructed than others, it is incredible that the most perfect 
one really understands rhythm, one can reproduce it, review it, tap one's fingers to it, and also click one's tongue or wiggle one's body to it. Rhythm, for Donald, is an example of something that can be observationally tracked and that reveals the ability and desire to imitate others, thereby suggesting an urge to communicate with others.

This seems to distill thythm to both a necessary component (or precondition) of language, and a phenomenon that can be manifested in the body in something such as dance. For the purposes of this paper, I will take the essential features of rhythm (that we care about in the study of cognition) to be the intentional construction of sound events in temporal patterns, and/or some recognizable behavioral response to sound events in temporal patterns. This definition fits Donald's well enough to ensure that no question is begged against the position, and defines the terminology such that we do not talk past one another. A generation of a rhythmic sound pattern must emerge spontaneously and if repeated by another individual, at least have the context suggest that the imitation is intentional and potentially communicative. This definition also does not demand that I produce dancing dolphins or coyote cha-chas to make progress in support of the main thesis.

This definition of rbythm also resonates with Brandt's notion of rhythmic pattern as an integral part of language: "In all known languages, regular intonation patterns connect lexical items and syntactic constructions $[. .$.$] and$ dialogical rhythms of turn-taking and attunement to emotionally determined styles of legato, staccato, or rubato phrasing in different tempi are important for the proper use of language in conversation and in the performance of speech acts." (Brandt forthcoming). In other words, my definition of rbythm allows it to be connected to human language and musical use in a way that is supported by research (Patel \& Daniele 2003) but does not automatically exclude animals from participation in it, as Donald claims. However, the thesis - that animals do participate in some forms of non-musical rhythm - does open the way for us to think beyond another of Brandt's claims. He tells us: "Musical perception and performance may" be at the origin of human language and symbolization; the esthetics of singing, playing and dancing creates symbolic meaning, which creates abstract thinking." (Brandt 2002). This view

ape or parrot of its species, should not in this be equal to the most stupid infant of its kind or at least to one that was crack-brained, unless the soul of brutes were of a nature wholly. different from ours" (Descartes 1889: 47). 
has been corroborated by Patel and Daniele (2003). Perhaps musical perception and performance is not necessarily the only way to access and express rhythmic understanding. In other words, if rhythm is a component of music, then perhaps rhythm precedes music and can generate some forms of abstract cognition without depending on music to bring us there. Music may be one path to abstract cognition, but rhythm may be the royal road to it, providing a venue for music as well as other forms of expression that motivate us to use language and symbolic structures. ${ }^{2}$ I will now attempt to give some evidence for this view. Some of the evidence is anecdotal, calling for further research and aimed only to raise curiosity and further discussion. Other evidence is well substantiated scientifically, and shoulders most of the burden for my contention that rhythmic understanding is present in at least some non-human minds.

\section{Example 1: Dolphin Signature Whistles}

Tursiops truncatus dolphins (the stars of the popular television show "Flipper") were reported to produce a specific, identifying whistle pattern repeatedly when separated from others in their pod by the Caldwells in the early 1960s (Caldwell \& Caldwell 1965). Signature whistles are, simply defined, temporally regulated, repeated frequency patterns used in a variety of contexts that seem to serve the purpose of self-and-other identification among dolphins. They are usually described as individualized, persistent, unique frequency patterns emitted by each dolphin fairly regularly. ${ }^{3}$ Many signature whistles contain regular loops or specific time patterns that distinguish them from the whistles of others (see spectrographs below).

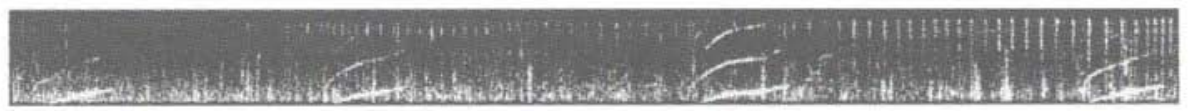

Spectrograph 1. Repeated, temporally patterned whistle of tursiops truncatus dolphin, with three barmonic steps, recorded in La Jolla, CA in February of 2001. Processed in Avisoft.

2 Brandt blurs my distinction between thythm and music, perhaps rightly. He has suggested that "Melodic names exist of course both in human cultures and in certain animal cultures $[\ldots]$ rhythm is cyclic grouping of beats, produced, perceived and shared intersubjectively [...] but thus determined, it IS already music, even if not tonal: Drum solos are music, etc." extracted from a personal communication. 9/15/2007.

3 Several studies of signature whistles have been done since the original Caldwell study. A brief survey of the literature suggests that between $25 \%$ and $85 \%$ of dolphin vocalizations are signature whistles, and the percentage seems to be influenced by the context, i.e., a dolphin separated from the pod will increase signature whistle frequency (Caldwell \& Caldwell 1965, McCowan \& Reiss 2001, Cook et al. 2004). 


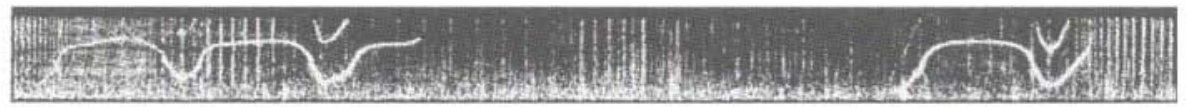

Spectrograph 2. Repeated whistle of tursiops truncatus dolphin with one barmonic step at the end of the looping frequency patterm. Recorded in La Jolla, CA, in February of 2001. Processed in AviSoft.

According to Sayigh's research (Sayigh et al. 2004), the signature whistles of young dolphins are learned, not innate, and develop over (approximately) the first 6 months of life, through repeated exposure to the whistles of other pod members, and rehearsal of the particular whistle by the neonate in question. Indeed, signature whistles diverge in pattern in evolutionarily reasonable ways in accordance with exposure and group composition. Female calves tend to develop signature whistles that are distinct from the mother's patterns (presumably because they will be inhabiting the same pod for a lifetime and need to be easily distinguishable from one another) while males will develop whistles that are very like those of the mother (presumably because adult males roam great distances and so are served by being able to identify the mothers and sisters upon returning to their original pod). Dolphins, in uttering signature whistles, seem to meet the first of Donald's criteria for rhythmicity, i.e., spontaneously produced patterns of sound, used without training, in what is apparently a communicative, or at least information bearing way. The remaining criteria to be fulfilled are 1) spontaneous imitation; 2) rehearsal; 3) modification of these whistle based sound patterns, and the research suggests that the answer is positive.

Recent work (Janik et al. 2006) has suggested that dolphins recognize each others' signature whistle frequency (pitch) patterns independently of their individual vocal quality features, i.e., dolphin subjects would attend to a soundproducing speaker longer when it played computer generated signature whistle patterns of dolphins closely related to the subject than when whistle patterns of unknown dolphins were played. That is, it is the specific rhythmic pattern of tones in the signature whistle, and not the timbre or quality of dolphin "voice" that provokes the recognition response in other dolphins. If it is a name, it is a name no matter which dolphin utters it.

There is evidence that dolphins will spontaneously mimic signature whistles of other dolphins (as well as other whistles, showing clear propensity for imitation) in the right contexts. Dolphins have been observed in the wild imitating each other's whistles and using the signature whistles of offspring that have been traveling far away from the pod (Janik 2000). Further, Sayigh (Sayigh 
et al. 2004) showed that neonates spontaneously vocalize to create signature whistles in response to conspecifics in the same pod (especially the mother) and that these vocalizations remain reliable indicators for individuals for more than 10 years.

Signature whistles, then, as rhythmic patterns of sound, are spontaneously produced by individual dolphins, imitated by other proximate or related dolphins, and rehearsed as each dolphin develops his or her own unique and rhythmic pattern. They are modified as individual offspring develop, and have been shown to converge when dolphins form alliances, suggesting that modification continues past what might be thought of as a critical period.

But is this intentional? Do dolphins really have rhythm (though perhaps not music) as humans do? As we cannot share the subjective states of dolphins, we must rely on other corroborative research. Dolphins do show self-awareness, as indicated by mirror-mark studies (Reiss \& Marino 2001), as well as the ability to recognize pod mates on a television screen. Thus, there is evidence that they have some notion of themselves as individuals within a group, as specific selves that can imitate the sounds of others and navigate both physically and socially by producing and mimicking specific temporal patterns of sound.

\section{Example 2: Coyote Calls}

Laundre (1981) notes that coyote calls, like other canine vocalizations, vary not only with season but also with time of day. This sort of regularity and predictability can only be considered 'rhythm' in the most uninteresting of senses when we are considering the origins of and conditions for language and conceptualization. While there is less research present on the types and varieties of coyote calls, the fact that their calls can be classified suggests, if weakly, that the calls are a recognizable series of notes organized in a temporal way. Coyote calls do have rich patterns, as noted by McCarley and others, and can be distinguished one from another using classifying terms such as 'yip' and 'yipe', 'short-howl' and 'laugh'. Diverse vocalization patterns are distinguished from each other not only by pitch and duration, but by differences in "the sequences of combination of two or more different sounds." (McCarley 1975).

Now of course, Donald wants, for a true understanding of rhythm, more than the spontaneous production of a recognizable patterned and repeatable sound structured in part by the timing of notes (lest birds have rhythm just by having a morning song, even if the song is entirely innate and unmodifiable by stimuli). To really be rhythm in a sense that is meaningful as a precursor or 
assistant to cognition and cognitive development, it must be spontaneously imitated, rehearsed and modified - and a simple call that is occasionally repeated is not thythmic. Rather, a pattern of calls in a specific order and with a temporal structure is a more rigorous, and convincing, standard.

Based on my own preliminary research ${ }^{4}$, the call of one coyote to its pack upon finding food (placed by myself in surroundings near a microphone for recording) is distinct not only in pitch and duration but also in rhythm. There is a very specific, high, short yip, followed by a pause about 3 times the length of the yip, followed by a longer, fluctuating, sine-wave like, undulating howl. The pack responds with a chorus howl. As I have recorded it, the food call is consistent from pack to pack, unmistakable, and effective: the pack arrives in short order. There is a clear and distinct sequence and combination of different sounds, and an unquestionable thythm, i.e., recognizable timing and beat, to the call. ${ }^{5}$ The pack does convert this call into action quite regularly, as Donald requires, by merging over nearby hills to attend to the food source.

A preliminary survey of coyote vocalization data stored at Cornell's MacAulay Library ${ }^{6}$ of natural sound lends some credence to my observations. In several different samples of coyote calls taken at a variety of different times and locations, there are further examples of the food call (especially recording no. 55334), and an instance of a coyote howling in response to a human's provocative howls, thus meeting another of Donald's requirements: that the calls be made in some context of communication broadly construed, i.e., the call was made to communicate information, or in response to another call: spontaneous imitation. Further anecdotal evidence of coyotes spontaneously responding to / returning howl calls has been noted copiously at Wolf Park in

42 instances of recording the calls of two distinct coyote packs upon finding food, at two different locations in CA separated by about 300 miles, both in 2002. I collected about 15 minutes of vocalization data in each instance, with vocalizations disbursed orer two eight hour periods, with similar results. Thanks to Chris Barczys, Bob Christie, John Fentiman, and Greg Budney for assistance with technological matters.

5 While there is a dearth of scientific research on coyote calls, there is an astounding market for them, as many are interested in bringing forth animals thought to be troublesome in order to kill or contain them. The sales potential for these calls shows that they are recognizable both to humans and to other coyotes, even while the science of such matters is still incunabular.

6 Specifically note, but examples are not limited to, recordings no. 118648, 116325 (response howls), 55334. 
Indiana, where wolves and coyotes are housed within 7 acres of space. Wolves regularly start the howl, and coyotes answer.'

The initial evidence that coyotes are more than merely cacophonous, then, is somewhat promising, though incomplete. Donald's criteria calling for spontaneous rehearsal and modification of patterned sound into isomorphically patterned bodily motion (e.g. from head bobbing to foot tapping) simply has not been researched in the canis latrans population.

\section{Conclusion}

If rhythm is a precedent to language and symbolic meaning, then we find the dolphins are swimming right along beside us, and the coyotes may be nipping at our heels in the race for semiotic sophistication. These two top-of-the-foodchain pack predators may well process and produce rhythm, approximately as Donald defines it, using their well socialized brains. We have seen that these creatures approximate Donald's criteria in their signature whistles and food calls, revealing repeated temporal patteming, spontaneity of production, mimicry and active response. Dolphin neonates exhibit rehearsal, while coyote sound production invites further research. While it is not clear that these creatures are musical in the fullest of senses, they clearly show the ability to create and use rhythmic patterns in an apparently intentional, communicative way. This suggests that rhythmicity may be crucial for the development of communicative systems among social species.

\section{References}

Bermudez, J. L. (2003). Thinking witbout Words. Cambridge: Oxford University Press

Brandt, P. Aa. (2002). Music and the Abstract Brain. PLAISIR. The Pleasure of Art as Sensed by the Brain: The First Intemational Conference on Neumesthetics. University of California at Berkeley, California.

Brandt, P. Aa. (forthcoming). Music and How We Became Human: A View from Cognitive Semiotics (draft of article for anthology by C. Trevarthen and S. Malloch) white paper available at http://www.case.edu/artsci/dmll/larcs/PerAagesecondpage.html. $22 / 11 / 2007)$

Caldwell, M. C. \& Caldwell, D. K. (1965). Individualized whistle contours in bottlenosed dolphins (Tursiops truncatus). Nature 207, $434-435$.

7 Preliminary research by Jeremy Safran, Robin Schulze, and William Issa (unpublished white paper) also brings corroborating evidence to claims of coyote howl response to wolves and to people who initiate howling. 
Cook, M. L. H., Sayigh, L. S., Blum, J. E., \& W'ells, R. S. (2004). Signature-whistle production in undisturbed free-ranging bottlenose dolphins (Tursiops truncatus). Proc. R. Sor. B. 271(1543), 1043-1049.

Descartes, R. (1889). Discourse on Method. Boston: Collier Press.

Donald, M. (1991). Origins of the Modern Mind. Cambridge: Harvard Lniversity Press.

Hauser, M. (2000). Wild Minds. NY: Henry Holt \& Co.

Janik, V.M., Sayigh, L.S., \& Wells, R. S. (2006). Signature whistle shape convers identity information to bottlenose dolphins. PNAS 103 (21), 8293-8297.

Janik, V.M., (2000) Whistle matching in wild bottlenose dolphins (Tursiops truncatus). Science 289, 1355-1357.

Laundre, J. (1981). Temporal Variation in Coyote Vocalization Rates. Joumal of W'ildife Management 45(3), 767-769.

McCarley, H. (1975). Long Distance Vocalizations of Coyotes. Joumal of Mammalog' $56(4), 847-856$.

McCowan, B \& Reiss, D. (2001). Quantitative Comparison of whistle repertoires from captive adult bottlenose dolphins (Delphinidae; Tursiops truncatus): a re-revaluation of the signature whistle hypothesis. Ethology 100, 194-209.

Patel, A. D. \& Daniele, J. R. (2003). An empirical comparison of thythm in language and music. Cognition 87, B35-B45.

Reiss, D. \& Marino, L. (2001). Mirror self-recognition in the bottlenose dolphin: a case of cognitive convergence. PNAS 98 (10), 5937-5942.

Sayigh, L. S., Tyack, P. L., Wells, R. S., \& Scott, M. D. (2004). Signature whistles of free-ranging bottlenose dolphins Tursiops Truncatus: stability and mother-offspring comparisons. Bebavioral Ecology and Sociobiology 26, 1640-1658. 